\title{
Professional Bodies Can Help in the Transition from Medical Researcher to Medical Educator
}

\author{
David J. Wilson
}

Published online: 28 February 2015

(C) International Association of Medical Science Educators 2015

\section{Dear Editor}

Benoit and Gould's commentary [1] is valuable and timely. Their description of the increasing divergence between research/laboratory-based scholarship and education-based scholarship is equally true for medical schools in the UK. As in the USA, UK government-imposed financial austerity to reduce the budget deficit is impacting upon the availability of research grants. This has coincided with the Research Excellence Framework (REF2014) [2] - the latest assessment of research quality in higher education institutions (HEIs). This assessment has cranked-up the metrics: making it more challenging for researchers to be judged as producing research of a 'quality that is world-leading in terms of originality, significance and rigour'. Consequently, the number of academics submitted in the assessment fell, with some HEIs being quite selective in terms of staff submitted for scrutiny in REF2014. The UK biomedical and medical sciences have been affected, with medical researchers in transition to becoming medical educators.

Although not quite a paradigm shift in the Kuhnian sense, the change when making this transition is, as the authors rightly claim, something of a 'culture shock'. Perhaps, the most significant consideration is tenure/promotion criteria, which Benoit and Gould raise, but rather surprisingly, as their final commentary point. Teaching and education-based scholarship must be valued by institutions: the default view that 'anyone can teach' should not be accepted (and which, I suspect, is rooted in the acerbic adage from George Bernard Shaw's

\section{J. Wilson $(\triangle)$}

Centre for Medical Education, School of Medicine, Cardiff

University, The Cochrane Building, Heath Park Campus,

Cardiff CF14 4YU, Wales, UK

e-mail: wilsondj2@cf.ac.uk
Man and superman [3]: 'He who can, does. He who cannot, teaches.' and the mutation of this to 'He who can, does. He who cannot, teaches. He who cannot teach, teaches teaching'). Good teaching and pedagogic scholarship should be valued: there are qualifications and professional standards to be achieved by medical and medical science educators (such as those provided by Fellowship of the International Association of Medical Science Educators Fellowship [4], Membership of the Academy of Medical Educators [5], Fellowship of The Higher Education Academy [6]). All of these serve to professionally validate the capabilities of educators and this should be made clear to transitioning academics.

Benoit and Gould are to be congratulated on their advice to support the transition from medical researcher to medical educator. The only thing that should perhaps be added is that there are professional bodies who can help in this transition by 'badging' academics appropriately as medical educators. In doing so, it gives regulatory bodies and the public confidence that high-quality education and training of the medical workforce is being maintained.

\section{References}

1. Benoit E, Gould DJ. Supporting the transition from medical researcher to medical educator. Med Sci Educ. 2014. doi:10.1007/s40670-0140100-8.

2. Research Excellence Framework. http://www.ref.ac.uk/

3. Shaw GB. Man and superman. A comedy and a philosophy Constable \& Co Ltd, Westminster. 1903: p240

4. The International Association of Medical Science Educators. Medical Educator Fellowship. http://iamse.org/fellowship.htm

5. Academy of Medical Educators. Membership. http://www. medicaleducators.org/index.cfm/membership/

6. The Higher Education Academy. HEA Fellowships. https://www. heacademy.ac.uk/professional-recognition/hea-fellowships 